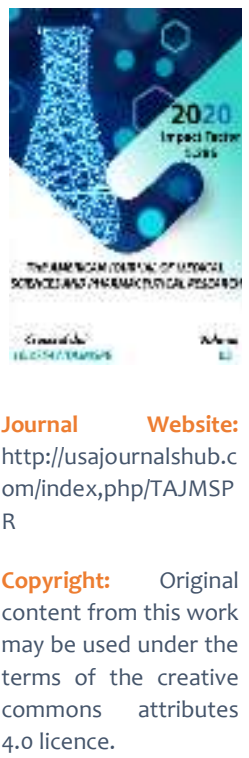

\section{Dysmetabolic Nephropathy In The Practice Of A Pediatrician}

Dilmuradova K.R.

Associate Professor, Doctor Of Medical Sciences; Neonatology Course At The Faculty Of Postgraduate Education, Uzbekistan

Akhmedova M.M.

Associate Professor, Candidate Of Medical Sciences; Department Of Pediatrics, Faculty of Postgraduate Education, Uzbekistan

Abdullaev D.M.

Associate Professor, Ph.D. Department Of Dermatovenereology, Uzbekistan

Mamatkulov T.A.

Assistant Of The Course Of Neonatology At The Faculty Of Postgraduate Education Samarkand State Medical Institute, Uzbekistan

\title{
ABSTRACT
}

The study involved 2850 children with dysmetabolic nephropathies at the age from 1 month to 3 years. The study showed that dysmetabolic nephropathy is a genetically determined pathology with early manifestation, which is often found in the practice of a pediatrician and requires medical examination on a family basis.

\section{KEYWORDS}

Dysmetabolic nephropathy, children, renal function, genetic analysis, family medical examination.

\section{INTRODUCTION}

Dysmetabolic nephropathies, among kidney lesions in children, are currently the predominant pathology $[1,4,7]$. This pathology accounts for up to $40 \%$ of kidney diseases in children, more often in young children $71.6 \%$ $[3,5,6]$. A feature of dysmetabolic 
nephropathies in children is occasional detection and latent course [4,10,]. It is known that a kind of ecological and physiological condition that characterizes the climatic features of the arid zone is a long-term heat load [10]. In the genetic analysis of the coefficient of predisposition to nephropathy for the additive interaction of genes with a threshold effect according to D. S. Falconer (1965), a high specific weight $(62.4 \pm 4.9 \%)$ of the genetic component in dysmetabolic nephropathies was established [8.9].

In order to carry out timely diagnosis and prevention of complications, information is needed on the features of functional and metabolic adaptation and seasonal variability of partial kidney functions in young children from families with a burdened nephrological history, taking into account the peculiarities of the climate of Uzbekistan.

We examined 285 children with nephropathy at the age of 1 month and older. up to 3 years old, treated in a specialized nephrology department of the regional children's multidisciplinary hospital. Among the examined boys there were 150, girls - 135. At the first stage of the research, screening tests were carried out: for bacteriuria (Griss test), calciuria (Sulkovich test), total sugars (Benedict test), cystinuria (iodine-azide test), protein (sulfosalicylic sample) and hyper aminoaciduria (ninhydri-new test) in the description of $\mathrm{Y}$. Todorov. The study of the genealogical and obstetric anamnesis, a quantitative study of urinary sediment, specialist consultations, as well as a centile assessment of physical development were carried out. The renal filtration function was assessed by the endogenous cretonne clearance. Tubular functions were judged by the Zimnitsky test, including the function of the proximal tubules - by the excretion of amino acids by high-voltage electrophoresis (E.A. Yureva et al., 1973), calcium (by the complex metric method by the method of Hacklen and Brabekova) and phosphorus (calorimetric method with ammonium molybdate; on the activity of distal tubules - on the excretion of ammonia and titratable acids in the description of I. Todorov (1963); on the function of Henle's loop - on the osmolarity of urine by the cryoscopy method on the OMK apparatus. A1C-01 Tubular phosphorus reabsorption (TRP) was calculated using the formula of Nordin and Frazer (1954).

In order to establish the seasonal characteristics of the response of the partial functions of the kidneys in the climatic conditions of Uzbekistan, in 15 healthy and 34 patients with oxalate nephropathy, we studied the state of ammonia acid genesis using accelerated loading according to O.M. Wrong (1971) and J. O. Davies (1972) 3\% ammonium chloride at $0.1 \mathrm{~g}$ per $\mathrm{kg}$ body weight. In different seasons of the year in order to establish adaptive reactions in 20 healthy and 33 children with dysmetabolic nephropathy. Partial kidney functions were studied in children using 1 and 2\% water load in the description of R.I. Aizman et al. (1981).

The quantitative determination of oxalates in daily urine was carried out according to the method of N.V. Dmitrieva (1966), urates according to Hopkins in the description of $\mathrm{O} \mathrm{V}$ Travina (1955), uric acid in blood and urine - by the Muller-Seifert method in the description V.G. Kolb and V.S. Kamyshnikova (1982).

The research results were processed on a computer - ES-1022. The comparison of samples was carried out according to the Student's test using the pair correlation coefficient. 
Genetic analysis was carried out using materials from 340 pedigrees of the probands we observed. The coefficient of inheritance of predisposition to nephropathy in the observed families was calculated according to D. S. Falconer (1965). At the first stage of the examination using screening tests, positive results were found in 817 children (27.2\%), which amounted to 272: 1000 examined. Noteworthy is the more than 3 times excess of positive reactions to saluria and erythrocyturia in the summer compared with the winter. In winter, a combination of leukocyturia with bacteriuria prevailed.

At the second stage, it was possible to confirm the presence of a pathological urinary syndrome in 222 patients, which accounted for $27.2 \%$ of those identified at stage I or 74: 1000 from the child population. Examination according to the stage III program revealed metabolic disorders in the form of hyperoxaluria, uraturia, cystinuria, hypercalciuria, and phosphaturia in $71 \%$ of young children. In $34.2 \%$ of them, nasaluria without urinary syndrome (diathesis) was established, in $21.6 \%$ of cases there was a layering of pyelonephritis, in $5.4 \%$ - interstitial nephritis and in $10.4 \%$ of cases - a complication of urolithiasis ... An analysis of the pedigrees of hospitalized patients revealed a familial burden of renal pathology in 1647 out of 2759 (59.7\%), in 266 cases - in relatives of the 1st degree of relationship $\left(9.6^{\circ} / \mathrm{s}\right)$. In this regard, in order to clarify the relative role of hereditary and environmental factors in the development of individual forms of nephropathy, we carried out a genetic analysis with the calculation of the coefficient of heritability of predisposition (h2) according to 340 pedigrees, where the probands were young children (Table 1) The coefficient of heritability of predisposition according to S. Falconer (1965) in the sample of children with nephropathy of metabolic genesis - $61.1 \pm 4.9 \%$ (from $48.1 \pm 8.4$ to $89.8 \pm$ $11.42 \%$ depending on the degree of $\neg$ statement to the proband). This indicator in the sample of patients with uraturia was $62.3 \pm 4.91$, with oxaluria $-47.3 \pm 5.7 \%$, in the group of patients with urolithiasis and interstitial nephritis against the background of calcium oxalate and uric acid crystalluria $-74.6 \pm 5,34 \%$. It was found that in the 1st sample, the total number of sick relatives was $31.2 \%$, in the 2 nd $-23.6 \%$, while in the control group - $19.5 \%$. The ratio of the incidence of nephropathy among the sick relatives of the indicated 3 groups was 21.3: 16.5: 1. In the sample of families with inbreeding, the frequency of nephropathy had a clear dependence on the degree of relationship with the proband.

Table 1.

Analysis of the inherited predisposition to nephropathy in children (according to D.S. Falconer 1965)

\begin{tabular}{|c|c|c|c|c|c|}
\hline \multicolumn{2}{|l|}{ Indication } \\
\hline Nosological groups and degree of kinship & $\mathrm{A}$ & $\mathrm{N}$ & $\mathrm{q}$ & $\mathrm{h}^{2}$ & SE\% \\
\hline 1 & 2 & 3 & 4 & 5 & 6 \\
\hline
\end{tabular}


The American Journal of Medical Sciences and Pharmaceutical Research (ISSN - 2689-1026)

Published: November 28, 2020 | Pages: 78-85

\begin{tabular}{|c|c|c|c|c|c|}
\hline $\begin{array}{l}\text { Control (total) } \mathrm{n}=38 \\
\text { Incl. }\end{array}$ & 59 & 2294 & 0,0257 & & \\
\hline 1 & 9 & 420 & 0,0214 & & \\
\hline 2 & 26 & 828 & 0,6314 & & \\
\hline 3 & 24 & 1046 & 0,0229 & & \\
\hline $\begin{array}{c}\text { Glomerulonephritis (total) } \mathrm{n}=36 \\
\text { Incl. }\end{array}$ & 35 & 1015 & 0,0345 & 11,0 & 9,97 \\
\hline 1 & 7 & 238 & 0,0294 & 41,3 & 17,45 \\
\hline 2 & 20 & 541 & 0,0369 & 6,88 & 12.17 \\
\hline 3 & 8 & 235 & 0,0339 & 6,08 & 15,62 \\
\hline $\begin{array}{c}\text { Dysmetabolic nephritis (total) } \mathrm{n}=266 . \\
\text { Including }\end{array}$ & 652 & 5764 & 0,1131 & 61,1 & 4,9 \\
\hline 1 & 233 & 1328 & 0,1755 & 89,8 & 11,42 \\
\hline 2 & 284 & 2952 & 0,0962 & 48,2 & 6,64 \\
\hline 3 & 135 & 1484 & 0,0909 & 48,06 & 8,4 \\
\hline Uraturia (total) $n=81$. Incl. & 174 & 1516 & 0,1148 & 62,3 & 4,91 \\
\hline 1 & 39 & 220 & 0.1773 & 82,02 & 20,8 \\
\hline 2 & 91 & 942 & 0,0998 & 50,2 & 8,72 \\
\hline 3 & 41 & 354 & 0,1158 & 60,1 & 11,16 \\
\hline Hyperoxaluria (total) $n=81$. Incl. & 191 & 2280 & 0,0838 & 47,3 & 5,7 \\
\hline 1 & 76 & 526 & 0,1445 & 79,04 & 2,82 \\
\hline 2 & 78 & 1208 & 0,646 & 30,2 & 8,71 \\
\hline 3 & 37 & 546 & 0,0678 & 34,7 & 10,3 \\
\hline $\begin{array}{l}\text { Urolithiasis + interstitial nephritis (total) } n= \\
\qquad 104\end{array}$ & 287 & 1968 & 0,1458 & 74,6 & 5,34 \\
\hline
\end{tabular}




\begin{tabular}{|c|c|c|c|c|c|}
\hline Including: & & & & & \\
\hline 1 & 118 & 582 & 0,2027 & 97,9 & 11,93 \\
\hline 2 & 112 & 802 & 0,1396 & 67,5 & 10,11 \\
\hline
\end{tabular}

Note: $A$ is the number of patients in the general population; $\mathrm{N}$-value of the total studied population; $\mathrm{h}^{2}$ - the coefficient of heritability of the predisposition; SE is the standard error of the predisposition.

This assumption was confirmed when calculating the coefficient of heritability of predisposition to nephropathy (h2). The share of the genetic component in inbred families was $66.5 \pm 6.76 \%$, and in the non-inbred sample - $51.4 \pm 7.7 \%$, which makes it possible to attribute family marriage to significant risk factors for a high frequency of nephropathy in the population, which must be taken into account in family medical examination.

In order to reveal the influence of weather conditions in the most contrasting seasons of the year in 20 healthy children and 33 patients with dysmetabolic nephropathy, we studied the features of partial renal functions. In healthy young children in summer compared with winter, minute urine output $(0.23 \pm 0.03$ $\mathrm{ml} / \mathrm{min}$ ) is lower due to a decrease in the glomerular filtration rate ' $(90.8 \pm 4.7 \mathrm{ml} / \mathrm{min}$ $1.73 \mathrm{~m} 2$ ). At the same time, the calcium clearance increased significantly $(0.89 \pm 0.08$ $\mathrm{ml} / \mathrm{min} / 1.73 \mathrm{~m} 2, \mathrm{P}<0.05)$. Stimulation of ammonio acidogenesis was noted: the excretion of ammonia averaged $68.7 \pm 4.2$ mmol per day $(\mathrm{Pi}=0.05)$ and titratable acids $92.1 \pm 4.8 \mathrm{mmol} /$ day $\left(\mathrm{P}_{1}<0.05\right)$. In contrast to healthy children, patients with noted nephropathies showed a significant increase in urine osmolarity ( $\mathrm{P} 1<0.01)$, which was accompanied by a decrease in urine output, ammonia excretion, and titratable acids ( $P$ $<0.05<0.001)$. This corresponded to a decrease in the concentration index in the summer, an increase in calcium clearance $(1.94 \pm 0.12 \mathrm{ml} /$ min $1.7 \mathrm{~m} 2, \mathrm{P}<0.001)$. Their decrease in patients with oxalate and urate nephropathies during this period, apparently, is a manifestation of dysadaptation of the tubular apparatus and creates a predisposition to metabolic acidosis.

In all examined healthy and sick children, after $1 \%$ water load, a polyuric reaction developed, the severity of which depended on the child's age and the nature of the pathology. Thus, in healthy children under the age of 3 years, there was an increase in urine output by 5 times compared with the initial indicator, while in older children, on average, by 9 times, and in young patients with dysmetabolic nephropathies - only 3 times. times. So, 2 hours after giving a water load in the summer, children with dysmetabolic nephropathies released $40-50 \%$ of the amount of the introduced load, versus $60-65 \%$ in healthy children. Recovery of diuresis in healthy children was noted after 2 hours, and in patients only after 3.5 hours. The maximum decrease in urine osmolarity in patients with dysmetabolic nephropathy occurred later (at the 9oth minute) than in healthy people (at the 6oth minute), and its recovery was only at 150 minutes, without reaching the initial values.

The level of hydrouretic reaction observed in the winter period at $1 \%$ water load in hot periods of the year was obtained with only $2 \%$ water load, i.e., to stabilize the osmotic parameters of urine and wash out calculiforming and nephrotoxic substances during the period of heat load high-liquid regimen, which is 2 times higher than physiological daily 
requirements (200-250 ml / kg of body weight per day), but not exceeding 10-15 ml / kg per hour.

Observations using a load of ammonium chloride in 15 healthy and 14 patients with oxalate nephropathies in different seasons of the year revealed a distinct suppression of the ammonio-acidogenesis function in the summer in patients with dysmetabolic nephropathies: the ammonium coefficient in winter in healthy young children was $58 \%$, in summer $-56 \% \backslash$ and in patients - $43 \%$ and $26 \%$, respectively. The state of metabolic acidosis in children of this group persisted after 8 hours of observation, which indicates insufficient adaptive ability of renal function and the need for corrective alkalizing measures. These features of the functioning of the kidneys in nephropathies of metabolic genesis should be taken into account when justifying their dietary drug therapy. Seasonal changes in the studied parameters can also be due to adaptive changes in exchange. Blood uric acid indices in 50 young probands with urate nephropathy were $0.312 \pm 0.01 \mathrm{mmol} / \mathrm{L}$ on average, i.e. was higher than in 20 healthy people $-0.242 \pm 0.01$ $\mathrm{mmol} /$ L. $\mathrm{P}<0.001$.

Control studies on the effectiveness of treatment and health-improving measures were carried out according to the results of observation of 102 patients, who were divided into 4 groups. In the group of siblings with isolated biochemical disorders in the urine and crystalluria (24 children), a dietary correction, a high-liquid regimen (group 1) was prescribed. These children were identified in a targeted study of families where there were probands with dysmetabolic nephropathies.

20 patients with transient urinary syndrome on the background of hyperoxal and uraturia without extrarenal clinical manifestations were treated with a diet with the inclusion of tissue metabolism mediators (vit. B6 at a dose of 40$50 \mathrm{mg}$ per day, cocarboxylase, ATP) and drugs that improve solubility and excretion nephrotoxic and stone-forming metabolites, along with the treatment of intercurrent diseases that provoked the appearance of urinary syndrome (group II). 28 patients with manifest forms of dysmetabolic nephropathies, in addition to the aforementioned dietary medications, additionally received traditional therapy used in the treatment of interstitial nephritis, pyelonephritis and urolithiasis, as well as antioxidants: vit. A at a dose of 1000 units / year of life per day and vit. E at a dose of $3 \mathrm{mg} / \mathrm{kg}$ body weight for 3 weeks (group III). Some patients with manifest forms of dysmetabolic drugs, along with vitamins $A, E$, received xidiphon at a dose of $10 \mathrm{mg} / \mathrm{kg}$ body weight 2 times a day for 20 days (group IV). Usibsov at the stage of isolated hyperoxal- and uraturia, diet therapy and a high-liquid regimen contributed to a decrease in the excretion of oxalates and urates by $1 / 3$ of the initial level, an increase in urine output by $50 \%$, normalization of urine $\mathrm{pH}$, and restoration of the ammonio acidogenesis function. The absence of clinical manifestation was noted in $85 \%$ of the patients in this group, which allowed dietary correction and increased drinking regime to be attributed to the measures of primary prevention of metabolic nephropathy.

Group II patients showed a significant decrease in the excretion of uric acid, urates $(P<0.05)$, a tendency to a decrease in the excretion of oxalates, phosphorus, calcium, ammonia, titratable acids, tubular reabsorption of phosphorus, the level of uric acid in the blood and activity xanthine oxidase $(P>0.05)$. Stable normalization of the function of ammonio acidogenesis, diuretic and osmoconcentrating 
functions of the kidneys occurred only by 6 months. observation.

In the fourth group of patients who received, along with antioxidants, xydiphon, by the end of the first week of treatment, urinary syndrome normalized, crystalluria, leukocyte and erythrocyturia disappeared, which indicated the anti-inflammatory effect of xydiphon. The concentration function of the kidneys improved, and the daily diuresis increased. Excretion of oxalates reached the level of healthy children $112.6 \pm 18.4 \mathrm{mmol} / \mathrm{s}$ (P $<0.01)$. The ammonia level increased to $46.2 \pm$ $4.0 \mathrm{mmol} / \mathrm{s}$ with the initial $22.0 \pm 4.5(P<0.01)$, titrated acids up to $50.4 \pm 6.2 \mathrm{mmol} / \mathrm{s}(\mathrm{P}<0.01$ ), the clearance of calcium and phosphorus was normalized, which, apparently, is associated with the ability of diphosphonates to bind calcium ions. Tubular phosphorus reabsorption reached a level in healthy children of $88.0 \pm$ $12.5 \%$ ( $P<0.05)$. The content of xanthine oxidase normalized $-109.0 \pm 16.8$ compared with the initial $302.6 \pm 18.2 \mathrm{mmol} / \mathrm{L}$ "1-sec, 'P <0.001). The level of uric acid in the blood reached the level in healthy children $(P<0.001$ ).

\section{CONCLUSION}

Thus, the conducted clinical, biochemical and genealogical analysis of dysmetabolic nephropathies makes it possible to speak in favor of their high prevalence and genetic determination in children with early manifestation, which dictates the need for increased alertness of pediatricians and timely prevention of their complications.

\section{REFERENCES}

1. Akhmedova $M M$ et al. Differential diagnosis of renal lesions of metabolic genesis in young children. // Achievements of science and education. 2019. No. 12 (53).

2. Akhmedzhanova N.I., Dilmuradova K.R. "Renal tubage" for chronic pyelonephritis in children. // Modern scientific bulletin. No. 9 (256), 2015. P.34 - 38. Belgorod.

3. Akhmedzhanova N.I., Dilmuradova K.R. Renoprophylaxis in secondary chronic pyelonephritis in children. - // Consilium (Izhevsk), 2016.-№2.-p.39-41.

4. Long V.V., Ignatova M.S. and other Dysmetabolic nephropathy in children. // Russian Bulletin of Perinatology and Pediatrics. 2012.-№5.-p.36-42.

5. Ignatova M.S. Actual problems of childhood nephrology at the beginning of the XXI century. // Pediatrics. 2007.- №6 (86) - - p.5-14.

6. Ismailova Z.A., Yuldashev B.A., Akhmatov A.A. Chronic pyelonephritis in children with impaired uric acid metabolism: features of the anamnesis and clinical and laboratory characteristics. // Questions of Science and Education. -2019.-p. 165-176.

7. Ishkabulov D.I., Ishkabulova G.D., Abdurasulov F.P. Functional kidney reserve in children with dysmetabolic nephropathy. Sat. tr. conf. "Topical issues of pediatrics, neonatology and pediatric surgery." Stavropol.-2013. p. 112-113.

8. Ishkabulov DI, KR Dilmuradov, NA Karimov. Organization of medical care for children with family-based nephropathies. - Herald of the doctor, 2015.- No. 4.-p.32-37.

9. $\mathrm{Ni}$ AN, VI Luchaninova et al. The role of seasonal factors in the development of the urinary system in children. Russian Bulletin of Perinatal Pathology and Pediatrics, No.1, -2011.- P.41-46. 
10. Madani, S. T. Isfahami. Effect of levamisoli in steroid-dependent nefrotic syndrome / Iran J. / Kidney Dis. - 2010. - Vo. 14, No. 4 - P. 292-296 